\title{
Electrochemical synthesis and potential electrochemical energy storage performance of nodule-type polyaniline
}

Y. H. Navale ${ }^{\mathrm{a}}$, S. T. Navale ${ }^{\mathrm{b}}$, M. A. Chougule ${ }^{\mathrm{a}}$, S. M. Ingole ${ }^{\mathrm{a}}$, F. J. Stadler ${ }^{\mathrm{b}}$, Rajaram S. Mane ${ }^{\mathrm{c}, \mathrm{d}^{*}}$, Mu. Naushad ${ }^{\mathrm{d}}$ and V. B. Patil ${ }^{\mathrm{a} *}$

${ }^{\mathrm{a}}$ Functional Materials Research Laboratory, School of Physical Sciences, Solapur University, Solapur - 413255, M.S., India

${ }^{\mathrm{b}}$ College of Materials Science and Engineering, Shenzhen Key Laboratory of Polymer Science and Technology, Guangdong Research Center for Interfacial Engineering of Functional Materials, Nanshan District Key Lab for Biopolymers and Safety Evaluation, Shenzhen University, Shenzhen 518060, PR China

${ }^{\mathrm{c}}$ Center for Nanomaterials \& Energy Devices, Swami Ramanand Teerth Marathwada University, Dnyanteerth, Vishnupuri, Nanded, 431606, India.

${ }^{\mathrm{d}}$ Department of Chemistry, College of Science, Bld-5, King Saud University, Riyadh, Saudi Arabia.

\begin{abstract}
Nodule-type polyaniline (PAni) has been successfully electrosynthesized onto conducting substrate and envisaged in electrochemical supercapacitor (ES) application as a potential energy storage electrode. Various bands are confirmed from the X-ray photoelectron and Fourier transform infrared spectra. Each nodule is of $\sim 100-200 \mathrm{~nm}$ in length and $20-80 \mathrm{~nm}$ in diameter. The $\sim 45^{\circ}$ surface water contact angle with water of PAni surface can be beneficial for accessing an entire electrode area with minimum interfacial resistance loss when is in contact with the aqueous electrolyte for ES application. The PAni nodule-type electrode when electrochemically characterized using cyclic-voltammetry and galvanostatic charge-discharge measurements has demonstrated a specific capacitance of $\sim 508$ F.g ${ }^{-1}$, a specific energy of $32.12 \mathrm{Wh} . \mathrm{kg}^{-1}$, a specific power of $13.39 \mathrm{~kW} \cdot \mathrm{kg}^{-1}$ and a Coulombic efficiency of $100 \%$ in $1 \mathrm{M} \mathrm{H}_{2} \mathrm{SO}_{4}$ electrolyte solution. An occurrence of $70 \%$ retention of initial capacity even after 5000 cycles is supporting for energy-storage application. Two separate redox reaction behaviors are confirmed in the discharge measurement.
\end{abstract}


Keywords: Supercapacitor; Cyclic voltammetry; Electrosynthesis; Morphology analysis; Charge transportation;

*Authors to whom all correspondence can be addressed. Emails: drvbpatil@gmail.com (V. B. Patil, Prof.) and rajarammane70@ srtmun.ac.in (R. S. Mane, Prof.).

\section{Introduction}

Research on electrochemical supercapacitors (ES) is a key technology in developing energy devices of high-power delivery within a short time and high energy storage potential. ES devices find applications in short-term power sources, including mobile electronic devices and hybrid electric vehicles [1, 2]. In ES, separation (of charges) takes place at the electrode/electrolyte interface and, thereby, charges store in two categories i.e. redox supercapacitor, in which the Faradic reactions take place at the electrode surface called pseudocapacitance, and electrical double layer capacitor, where the separation of charges is confirmed within electrode materials along with electrode/electrolyte interface. Ruthenium oxide is a key material for this application; however, its cost impedes its commercial use. Therefore, researchers nowadays are looking at alternative materials including polymers, metal oxides, carbons and more recently MXene etc. Similar to sensitivity in chemical gas sensors and power conversion efficiency in solar cells in addition to energy density and power density, specific capacitance (SC) is one of the important electrochemical parameters in ES devices. Electrodes of these materials have; hierarchical (nanowires and nanosheets) morphology, high surface area and SC value. Conducting polymers such as polyaniline (PAni), polypyrrole and polythiophene have proven their importance as electrode materials in ES application [3-8] owing to their availability of low-temperature synthesis methods, eco-friendliness, and possibility of deposition onto a wide variety of substrates $[9,10]$. The high conductivity, low density, and mechanical flexibility of PAni have made it an important electrode material not only in ES devices but also in battery and gas sensor applications too [11]. Additionally, its oxidation states are readily changing compared to others [12], which have direct importance in energy storage devices. Various morphologies of PAni like nanowires [13, 14], nanofibers [15], and nanograins [16] etc., are being reported for above-listed applications. 
In this work, we demonstrate the synthesis of PAni electrode composed of nodule-type morphology onto a conducting stainless-steel (SS) substrate by using three-electrode electrosynthesis method which further is characterized by X-ray photoelectron spectroscopy (XPS), Fourier-transform infrared (FT-IR) spectroscopy, field-emission scanning electron microscopy (FESEM), transmission electron microscopy (TEM), atomic force microscopy (AFM), and contact angle etc., measurement techniques for confirming the surface architecture and wettability, chemical composition, and topography with roughness etc. The ES properties of the PAni electrode are obtained using cyclic voltammetry (CV), charge-discharge and electrochemical impedance spectroscopy (EIS) measurements in $1 \mathrm{M} \mathrm{H}_{2} \mathrm{SO}_{4}$ electrolyte.

\section{Experimental and characterization details}

The PAni electrode was synthesized onto SS in presence of $0.1 \mathrm{M}$ aniline and $0.1 \mathrm{M}$ $\mathrm{H}_{2} \mathrm{SO}_{4}$. Initially, $0.1 \mathrm{M}$ aniline and $0.1 \mathrm{M} \mathrm{H}_{2} \mathrm{SO}_{4}$ were dissolved separately in $100 \mathrm{~mL}$ doubledistilled water. Both solutions were mixed together in a single beaker and stirred for 1-2 $\mathrm{h}$. Prior to its direct use, pieces of SS substrate $\left(4 \times 1.5 \mathrm{~cm}^{2}\right)$ were washed with doubled-distilled water and acetone followed by ultrasonic cleaning for $30 \mathrm{~min}$. A graphite plate $\left(4 \times 1.5 \mathrm{~cm}^{2}\right)$ was used as the counter electrode and saturated calomel electrode (SCE) as the reference electrode in conventional three-electrode electrodeposition system. The deposition of the PAni electrode was carried out at current densities between 2 and $6 \mathrm{~mA} / \mathrm{cm}^{2}$ and in potential window of 1.0-1.8 V vs. SCE. After deposition, PAni electrodes were washed several times under running water to remove loosely bonded low-molecular weight organic intermediates and oligomers and then dried at room temperature before the use. The mass of the PAni electrode was measured by a weight difference method using sensitive microbalance. The nodule-type surface morphology of PAni electrode was confirmed from FESEM (Model: MIRA3 TESCAN, USA, operated at 10 $\mathrm{kV}$ ) plane-view digital images. The elements were confirmed by using XPS (VG, Multilab 2000, Thermo Scientific). The AFM images obtained using a SPA-300 HV unit. Surface wetting behavior was confirmed from the water contact angle measurement unit (Rame-hart, USA, equipment with CCD camera). The ES measurements were measured in a custom designed beaker-type electrochemical cell equipped with i.e. PAni (working), graphite (counter), SCE (reference) electrodes in $1 \mathrm{M} \mathrm{H}_{2} \mathrm{SO}_{4}$ aqueous electrolyte solution. The $\mathrm{CV}$ (at various scan rates 
ranging from 5 to $100 \mathrm{mV} \mathrm{s}^{-1}$ within the potential range of $-1.0-1.0 \mathrm{~V}$ (vs. SCE)), galvanostatic charge-discharge, and EIS (with AC voltage amplitude $5 \mathrm{mV}$, frequency range from 0.1 to $1 \mathrm{k} \mathrm{Hz}$ at $0.5 \mathrm{~V}$ ) measurements were operated on $\mathrm{CHI} 680 \mathrm{C}$ electrochemical workstation. Schematic view of synthesis of PAni electrode is shown in Fig. 1.

\section{Results and discussion}

\subsection{Elemental, FTIR and Raman shift analyses}

Fig. 2 (a-d) highlights the wide range and individual C1s, O1s and N1s XPS core level spectrums. The wide range XPS survey spectrum (fig. 2 (a)) has demonstrated C, O, and N elemental peaks. In Fig.2 (b), high resolution C1s spectrum is centered at 284.65 eV (C-C) [1719], while O1s (Fig. 2 (c)) and N1s (Fig. 2 (d)) core level XPS spectrums are located at $531.8 \mathrm{eV}$ (C-O, CH-OH, C=O) [20] and $399.3 \mathrm{eV}$ (single benzenoid amine (-NH-)), respectively. The observed XPS spectrum and corresponding binding energy values are in good agreements with that reported in the literature [17-20]. The FTIR measurement provides valuable information about the chemical bonding states of the sample materials. FTIR spectrum of the PAni electrode synthesized using electrodeposition method was measured in the range of $500-4000 \mathrm{~cm}^{-1}$ (Fig. 2(e)). The characteristic peaks obtained at 499, 822 , and $1136 \mathrm{~cm}^{-1}$ are assigned to the band characteristics of out-of-plane bending vibrations of $\mathrm{C}-\mathrm{H}$ of benzene rings and $\mathrm{B}-\mathrm{NH}-\mathrm{B}$ or $\mathrm{B}-$ $\mathrm{NH}-\mathrm{Q}$ bonds, respectively (where $\mathrm{B}$ refers to the benzenic-type rings and $\mathrm{Q}$ refers to the quinonic-type rings). The peak at $1298 \mathrm{~cm}^{-1}$ is attributed to the $\mathrm{C}-\mathrm{N}$ stretching vibration of PAni and the one at $1491 \mathrm{~cm}^{-1}$ is accounted for the $\mathrm{C}$ - $\mathrm{C}$ stretching of benzenoid rings. The peak at $1579 \mathrm{~cm}^{-1}$ can be indexed to the $\mathrm{C}=\mathrm{C}$ stretching of quinoid ring. Finally, the broad peak at $3417 \mathrm{~cm}^{-1}$ is due to the $\mathrm{N}-\mathrm{H}$ stretching mode [22-25]. Occurrence of these peaks at respective positions, without doubt, has corroborated the formation of PAni.

\subsection{Morphology and surface wetting studies}

The surface morphology of PAni electrode was analyzed from FESEM plane-view digital image [Fig. 3(a)]. From the FESEM images, uniformly distributed interconnected nodules of irregular dimensions are evidenced. Few PAni nodules are inclined and few are partially/fully were embedded at the bottom side of electrode by leaving tips in air. Polished-type nodules of higher dimensions are also evidenced. Each nodule is of $\sim 100-200 \mathrm{~nm}$ in length and 20-80 nm in 
diameter. We believed that this type of surface morphology shall be beneficial for more redox reactions as infiltration of electrolyte ions can be much easier than relatively compact/planar structure that eventually would enhance SC value. Obtained nodule-type morphology of PAni is consistent to TEM (discussed later). Fig. 3 (b) shows 2D AFM image of PAni electrode where an exact morphology i.e. surface appearance is unclear. The average roughness of the PAni electrode is $\approx 40 \mathrm{~nm}$, an essentially critical parameter in ES application as higher surface roughness value is promoting for extensive redox reactions [26-28]. Fig. 3(c) highlights TEM image of PAni, obtained by dispersing PAni into an ethanolic solution followed the collection onto copper grids. From the TEM image, it is clear that the dimensions of an individual nodule are close to that measured using FESEM image. Moreover, nodule-type morphology is confirmed once again. Controlling and modifying the surface wettability of solid surface are useful for redox reaction ability followed ES performance [29] for example hydrophics surface shows considerable electrolyte/electrode coverage whereas hydrophobic surface reveals pointtype contact. In general, if the wettability is high, contact angle $(\theta)$ will be small and surface is considered as hydrophilic. Fig. 3(d) shows the digital photograph of water contact measurement on PAni electrode surface. Interestingly, PAni electrode surface has exhibited hydrophilic behavior with $45^{\circ}$ water contact angle value i.e. $<90^{\circ}$. Generally, low water contact angle increases the electrochemical performance, where interfacial contact at electrolyte-electrode is considerable [30].

\subsection{Electrochemical measurements}

\subsubsection{Scan rate effect}

In order to recognize the supercapacitive capability of electrodeposited PAni electrode, electrochemical measurements were performed. Initially, the effect of scan rate on specific/interfacial capacitance on PAni electrode was investigated. The capacitance was calculated using $\frac{\mathbf{I}}{(\mathbf{d V} / \mathbf{d t})}$ relation, where ' $\mathrm{I}$ ' is the average current in $\mathrm{A}$ and $\mathrm{dV} / \mathrm{dt}$ is the scan rate. The SC value $(\mathrm{F} / \mathrm{g})$ of the PAni electrode was obtained by dividing the capacitance to weight dipped in the electrolyte using $\boldsymbol{C}_{\boldsymbol{s}}=\frac{\boldsymbol{C}}{\boldsymbol{W}}$ relation, where ' $\mathrm{W}$ ' is the weight of the active material on the SS substrate. The interfacial capacitance $\left(\mathrm{F} / \mathrm{cm}^{2}\right)$ was obtained by dividing the capacitance to area dipped in an electrolyte using $\boldsymbol{C}_{\boldsymbol{i}}=\frac{\boldsymbol{C}}{\boldsymbol{A}}$ relation, where 'A' is the area of the active material 
dipped in the electrolyte. The supercapacitive properties of PAni electrode were examined using $\mathrm{CV}$ spectra obtained for various scanning rates. The results of $\mathrm{CV}$ measurements are presented in fig. 4(a) within $-1.0-+1.0 \mathrm{~V}$ potential window for 5, 10, 20, 30, 40, 50, and $100 \mathrm{mVs}^{-1}$ scan rates in $1 \mathrm{M} \mathrm{H}_{2} \mathrm{SO}_{4}$ electrolyte solution. During the oxidation/reduction process, the positive charges exchanged at electrolyte and electrode interface can lead to develop the protons transfer process slow. At high scan rate, either depletion or saturation of protons is dominant in the electrolyte inside the electrode. During the redox process, an ionic resistivity is increased, leading to a drop of capacitance in the electrode $[31,32]$ and a part of PAni electrode can be inaccessible, hence, the SC value obtained at the slowest scan rate is considered to be closest to that of full utilization of the material. Fig. 4 (b) shows the variations of SC value and interfacial capacitance as the function of scan rate. The PAni film electrode has exhibited as high $508.70 \mathrm{~F} \mathrm{~g}^{-1} \mathrm{SC}$ value at $5 \mathrm{mV} \mathrm{s}^{-1}$ scan rate and is decreased to $187.41 \mathrm{Fg}^{-1}$ as the scan rate is increased from the 5 to 100 $\mathrm{mV} \mathrm{s}^{-1}$. The decrease in SC value at higher scan rate, is a common behavior, and is attributed to the involvement of inner active sites that are not taking part at high scan rates in redox reactions. The decrease in capacitance at high scan rate is confirming that the part of the surface of the electrode is inaccessible for redox reactions [31,32].

\subsubsection{Retention and charging/discharging measurements}

The long-term cycle stability is one of the most important aspects in SC application before scale up the process. The EP deposited PAni electrode is chemically stable up to 5000 cycles. Fig. 5 (a) shows CV scans of PAni electrode for $1^{\text {st }}, 2500^{\text {th }}$ and $5000^{\text {th }}$ cycle numbers at $100 \mathrm{mV} \mathrm{s}^{-1}$ scan rates where infinitesimal change due to stabilization process was evidenced. We infer that the SC value of PAni electrode is higher at lower rate i.e. $5 \mathrm{mV} \mathrm{s}^{-1}$ but it the process of redox reaction at this scan rate is too slow that can give any information about mechanical robustness of electrode along with chemical stability thereby stability measurement in the present work was performed at $100 \mathrm{mV} \mathrm{s}^{-1}$. The SC of PAni electrode is decreased from $212.85 \mathrm{Fg}^{-1}$ to $148 \mathrm{Fg}^{-1}$ after 5000 cycles and, thus, retained $\approx 70 \%$ of its initial capacity even after 5000 cycles, indicating the material potential for energy-storage application. The variation of SC value with cycle number is presented in fig. 5 (b) wherein SC value is decreased with scan rate. The slow decay rate of SC value is in support to the high cyclic stability of the PAni electrode. The specific and interfacial capacitance values are decreased with cycle number due to loss of active material caused by the dissolution or/and detachment, during the early charging and discharging 
cycles in the electrolyte. Charge/discharge behavior of PAni electrode (Fig. 6 (a)) was obtained at current density of $100 \mu \mathrm{A} \mathrm{cm}{ }^{-2}$ within the potential range of $-0.2-+0.8 \mathrm{~V} v s$. SCE in $1 \mathrm{M}$ $\mathrm{H}_{2} \mathrm{SO}_{4}$ electrolyte (with a representative cycle shown in fig. 6 (b)). From figure it is seen that the $\Delta \mathrm{V}_{1}$ changes quickly due to equivalent series resistance (ESR) of supercapacitor, the sharp changes in $t_{d}$ and $\Delta \mathrm{V}_{2}$ are caused by discharge time and voltage decrement, respectively [33]. The galvanostatic charge-discharge and cyclic voltammetry curves, obtained for 2, 3, 4, 5, and 6 $\mathrm{mA} \mathrm{cm}{ }^{-2}$ current densities, are obtained for knowing the suitability of PAni electrode in ES application. With increase of the deposition current, the mass of the deposited material is increased i.e. proportional to the time. The PAni electrode at $2 \mathrm{~mA} \mathrm{~cm}^{-2}$ current density has demonstrated the highest SC value i.e. 508.70 (at $5 \mathrm{mV} / \mathrm{s}$ ) - $212.85 \mathrm{Fg}^{-1}$ (at $100 \mathrm{mV} \mathrm{s}^{-1}$ ) and 100\% Coulombic efficiency. Table 1 depicts the current density dependent supercapacitive parameters of PAni electrode viz., SC $\left(\mathrm{F}^{-\mathrm{g}^{-1}}\right)$, interfacial capacitance $\left(\mathrm{Ci}, \mathrm{F} \mathrm{cm}^{-2}\right)$, specific energy (SE) $\mathrm{Wh} \mathrm{kg}^{-1}$, specific power (SP) $\mathrm{kW} \mathrm{kg}^{-1}$ and Coulombic efficiency $(\eta \%)$. The galvanostatic charge/discharge curve of PAni electrode is presented in fig 6 (a). Presence of non-linearity in all curves was indicating an involvement of the faradic reactions i.e. pseudocapacitance [34]. The initial drop in potential is accounted for the resistance. Under close inspection, two slopes can be clearly seen, suggesting involvement of double layer capacitance behavior in addition to Faradic reaction in an overall performance. These potentials can be minimized for lower charge/discharge current densities. The SC value was calculated by using $\frac{\boldsymbol{I} \mathbf{x} \Delta t}{\Delta \boldsymbol{V} \mathbf{x} \boldsymbol{m}}$ relation, where ' $\mathrm{I}$ ' is the charge/discharge current, ' $\Delta \mathrm{t}$ ' is the discharge time, ' $\Delta \mathrm{V}$ ' is the potential window, and ' $\mathrm{m}$ ' is the mass of active material. Developed PAni electrode has demonstrated considerable electrochemical reversibility with as high as $508.70 \mathrm{~F} \mathrm{~g}^{-1} \mathrm{SC}$ value. The SP and SE values of PAni electrode were calculated using $\frac{I \mathrm{XV} V}{m}$ and $\frac{I \mathrm{X} V}{m}$ relations, respectively [35]. Here, discharge current (I) is in Ampere, voltage range is in V, discharge time (t) is in second and mass of the material on the electrode is in gram.

\subsubsection{Charge transport kinetics}

The impedance measurement is used for conductivity studies and to elucidate the mechanism and kinetics of the chemical and electrochemical reactions involved [36]. Fig. 7(a) shows the Nyquist plots ( $Z^{\prime}$ vs. Z') of the PANi electrode measured in $1 \mathrm{M} \mathrm{H}_{2} \mathrm{SO}_{4}$ with an 
applied potential of $5 \mathrm{mV}$. The average value of $R_{\text {ele }}$ (resistance of electrolyte) was $2.46 \Omega$. The average value of the chare-transfer register $\left(R_{\mathrm{ct}}\right)$ is $34.6 \Omega$.

Table 1: The current density dependent ES parameters obtained for different scan rates.

\begin{tabular}{c|c|c|c|c|c}
\hline $\begin{array}{c}\text { Current } \\
\text { density } \\
\left(\mathrm{mAcm}^{-2}\right)\end{array}$ & $\begin{array}{c}\mathrm{SC} \\
\left(\mathrm{Fg}^{-1}\right) \\
(5-100 \mathrm{mV} / \mathrm{s})\end{array}$ & $\begin{array}{c}\mathrm{C}_{\mathrm{i}} \\
\mathrm{Fcm}^{-2}\end{array}$ & $\begin{array}{c}\mathrm{SE} \\
\left(\mathrm{Whkg}^{-1}\right)\end{array}$ & $\begin{array}{c}\mathrm{SP} \\
\left(\mathrm{kWkg}^{-1}\right)\end{array}$ & $\begin{array}{c}\text { Coulombic } \\
\text { efficiency } \\
\eta(\%)\end{array}$ \\
\hline 2 & $508.70-212.85$ & $0.038-0.014$ & 32.12 & 13.39 & 100 \\
3 & $430.00-168.41$ & $0.025-0.011$ & 33.89 & 13.36 & 99.86 \\
4 & $307.89-120.48$ & $0.023-0.009$ & 37.21 & 13.34 & 99.64 \\
5 & $281.12-120.48$ & $0.021-0.009$ & 37.61 & 13.36 & 98.45 \\
6 & $267.73-120.48$ & $0.020-0.009$ & 55.55 & 13.38 & 96.79 \\
\hline
\end{tabular}

From figure two i.e. high and low frequency regions are clearly seen. The frequency, at which a deviation from semicircle is observed, is known as 'knee' frequency, reflecting maximum frequency at capacitive behavior [37]. The presence of semicircle at the high frequency region and the straight line at the low frequency region ( $45^{\circ}$ to the real axis) is an indication of the capacitive behavior. Measured impedance data of PAni electrode was simulated using an equivalent circuit depicted (inset of fig. 7 (a)). Close agreement between the measured and simulated data is evidenced. Fig. 7 (b) shows the Bode plot of PAni electrode with phase angles at $46.71^{\circ}$ and $50.47^{\circ}$. The 0.17 and 1.66 loss factors of PAni electrode are obtained at $1 \mathrm{~Hz}$ and 1 $\mathrm{kHz}$ frequencies, respectively, which are in good agreement with the effect of scan rate on SC value, wherein SC value is higher for lower scan rate and vice-versa. Therefore, measurement at lower scan rate is considered to be ideal for better performance of the PAni electrode [38-40].

\section{Conclusions}

PAni electrode composed of nodule-type surface morphology was successfully prepared by electrodeposition method. Presence of characteristics bands and expected elemental peaks is confirmed from FTIR and XPS surface analyses. The $45^{\circ}$ water contact angle value is evidenced for hydrophilic surface nature, which favors for an excess infiltration of electrolyte ions for more redox reactions through wide range of area coverage. The PAni electrode has demonstrated a 
maximum specific capacitance of $\sim 508 \mathrm{~F} \mathrm{~g}^{-1}$ at $5 \mathrm{mV} \mathrm{s}^{-1}$ in $1 \mathrm{M} \mathrm{H}_{2} \mathrm{SO}_{4}$ electrolyte. The specific power and specific energy values estimated from the charge/discharge measurement are respectively found to be $13.39 \mathrm{~kW} \mathrm{~kg}^{-1}$ and $32.12 \mathrm{Wh} \mathrm{kg}^{-1}$ at $2 \mathrm{mAcm}^{-2}$ current density. About $70 \%$ of its initial capacity over 5000 cycles is retained indicating the material suitability in energy-storage device design.

\section{Acknowledgement}

Prof. V. B. Patil is thankful to the CSIR, for financial support through scheme no.03 (1319)/14/EMR-II. The authors (RSM and MN) extend their appreciation to the International Scientific Partnership Program ISPP at King Saud University for funding this research work through ISPP\# 0032. FJS would like to thank the National Science Foundation of China (21574086), Nanshan District Key Lab for Biopolymers and Safety Evaluation (No. KC2014ZDZJ0001A), Shenzhen Sci \& Tech research grant (ZDSYS201507141105130) and Shenzhen City Science and Technology Plan Project (JCYJ20140509172719311) for financial support.

\section{References}

[1] L. Cao, F. Xu, Y.Y. Liang, H.L. Li, Adv. Mater., 16 (2004) 1853.

[2] R.A. Huggins, Solid State Ionics, 134 (2000)179.

[3] J. Liu, M. Zhou, L. Z. Fan, P.Li, X. Qu, Electrochem. Acta, 55 (2010) 5819.

[4] H. Guan, L. Z. Fan, H. Zhang, X. Qu, Electrochem. Acta, 56 (2010) 964.

[5] X. Zou, S. Zhang, M. Shi, J. Kong, Solid State Electrochem., 11 (2007) 317.

[6] D. S. Dhawale, D.P. Dubal, V. S. Jamadade, R. R. Salunkhe, C. D. Lokhande, Synth. Mater., 160 (2010) 519.

[7] A. Lafargue, P. Simon, C. Sarrazin, J. F. Fauvarque, J. Power Sources, 80 (1999) 142.

[8] D. P. Dubal, S. V. Patil, W. B. Kim, C. D. Lokhande, Mater. Lett., 65 (2011) 2628.

[9] K. Li, D.C. Diaz, Y. He, J.C. Campbell, C. Tsai, Appl. Phys. Lett., 64 (1994) 2394.

[10] J. Janata, M. Josowicz, Nat. Mater., 2 (2003) 19.

[11] D. K. Bandgar, S. T. Navale, S. R. Nalage, R. S. Mane, F. J. Stadler, D. K. Aswal, S. K. Gupta, V. B. Patil, J. Mater. Chem. C, 3 (2015) 9461.

[12] E. T. Kang, K. G. Neoh, K. L. Tan, Prog. Poly. Sci., 23 (1998) 277. 
[13] V. Gupta, N. Miura, Electrochem. Solid State Lett., 8 (2005) A630.

[14] V. Gupta, N. Miura, Mater. Lett., 60 (2006)1466.

[15] D. S. Dhawale, R. R. Salunkhe, V. S. Jamadade, D.P. Dubal, S. M. Pawar, C. D. Lokhande, Curr. Appl. Phys., 10 (2010) 904.

[16] D. S. Dhawale, R. R. Salunkhe, V. S. Jamadade, T. P. Gujar, C. D. Lokhande, Appl. Surf. Sci., 225 (2009) 8213.

[17] R. Rajagopalan, J. O. Iroh, Appl. Surf. Sci., 218 (2003) 58.

[18] K. L. Tan, B. T. G. Tan, E. T. Kang and K. G. Neoh, Phys. Rev., 39 (1989) 8070.

[19] M. G. Han, S. S. Im, Polymer, 41 (2000) 3253.

[20] S. Golczak, A. Kanciurzewska, M. Falhman, K. Langer, J. J. Langer, Solid State Ionics, 179 (2008) 2234.

[21] X. Li, S. Tian, Y. Ping, D. H. Kim, W. Knoll, Langmuir, 21 (2005) 9393.

[22] S. G. Pawar, S. L. Patil, A. T. Mane, B. T. Raut, V. B. Patil, Arch. of App. Sci. Res., 2 (2009) 109.

[23] D. K. Bandgar , G. D. Khuspe , R. C. Pawar , C. S. Lee , V. B. Patil, J. Appl. Nanosci. , $2014,4,27$.

[24] M. S. Celly-Izumi, Vera R. L. Constantino, Anna M.C. Ferreira, Marcia L.A. Temperini, Synth. Met., 2000, 156,654.

[25] I. Baltog, M. Baibarac, L. Mihut, N. Preda, T. Velula, C. Bucur, M. Husanu, Rom. JPhys., 54 (2009) 677.

[26] R. M. Patrikar, C. Yi Dong, W. Zhuang, Microelectronics J., 33 (2002) 929.

[27] Y. P. Zhao, G.C. Wang, T.M. Lu, Phy.Rev. B, 60 (1999) 2.

[28] G. Palasantzas, De Hosson, Solid StateComm., 118 (2001) 203.

[29] M. M. Vadiyar, S. C. Bhise, S. K. Patil, S. S. Kolekar, A. R. Shelke, N. G. Deshpande, J. Y. Chang, K. S. Ghule , A. V. Ghule, Chem.Comm., 52 (2016) 2557.

[30] S.T. Navale, V.V. Mali, S. A. Pawar, R. S. Mane, M. Naushad, F. J. Stadler, V. B. Patil, RSC Adv., 5 (2015) 51961.

[31] J. N. Broughton, M. J. Brett, Electrochem. Solid State Lett., 5 (2002) 279.

[32] R. B. Rakhi, W. Chen, D. Cha, H. N. Alshareef, Nano Lett., 12 (2012) 2559.

[33] V. Ganesh, S. Pitchumani, V. Lakshminarayanan, J. Power Sources, 158 (2006) 1523.

[34] W. Shao, R. Jamal, F. Xu, A. Ubul, T. Abdiryim, Materials, 5 (2012) 1811. 
[35] W.C. Chen, T.C. Wen, H. Teng, Electrochem. Acta, 48 (2003) 641.

[36] A. SezaiSarac, M. Ates, B. Kilic, Int. J. Electrochem. Sci., 3 (2008) 777.

[37] X.F. Wang, D. B. Ruan, D. Z. Wang, J. Liang, Acta Phys. Chem. Sin., 21 (2005) 261.

[38] F. Pico, J. Ibanez, M. A. Lillo-Rodenas, A. Linares-Solano, R. M. Rojas, J. M. Amarilla, J. M. Rojo, J. Power Sources, 2008, 176, 417.

[39] S. Richard Prabhu Gnanakan, M. Rajasekhar, A. Subramania, Int. J. Electrochem. Sci., 2009, $4,1289$.

[40] K. Prasad, N. Munichandraiah, Electrochem. Solid State Lett., 2002, 5, 271. 


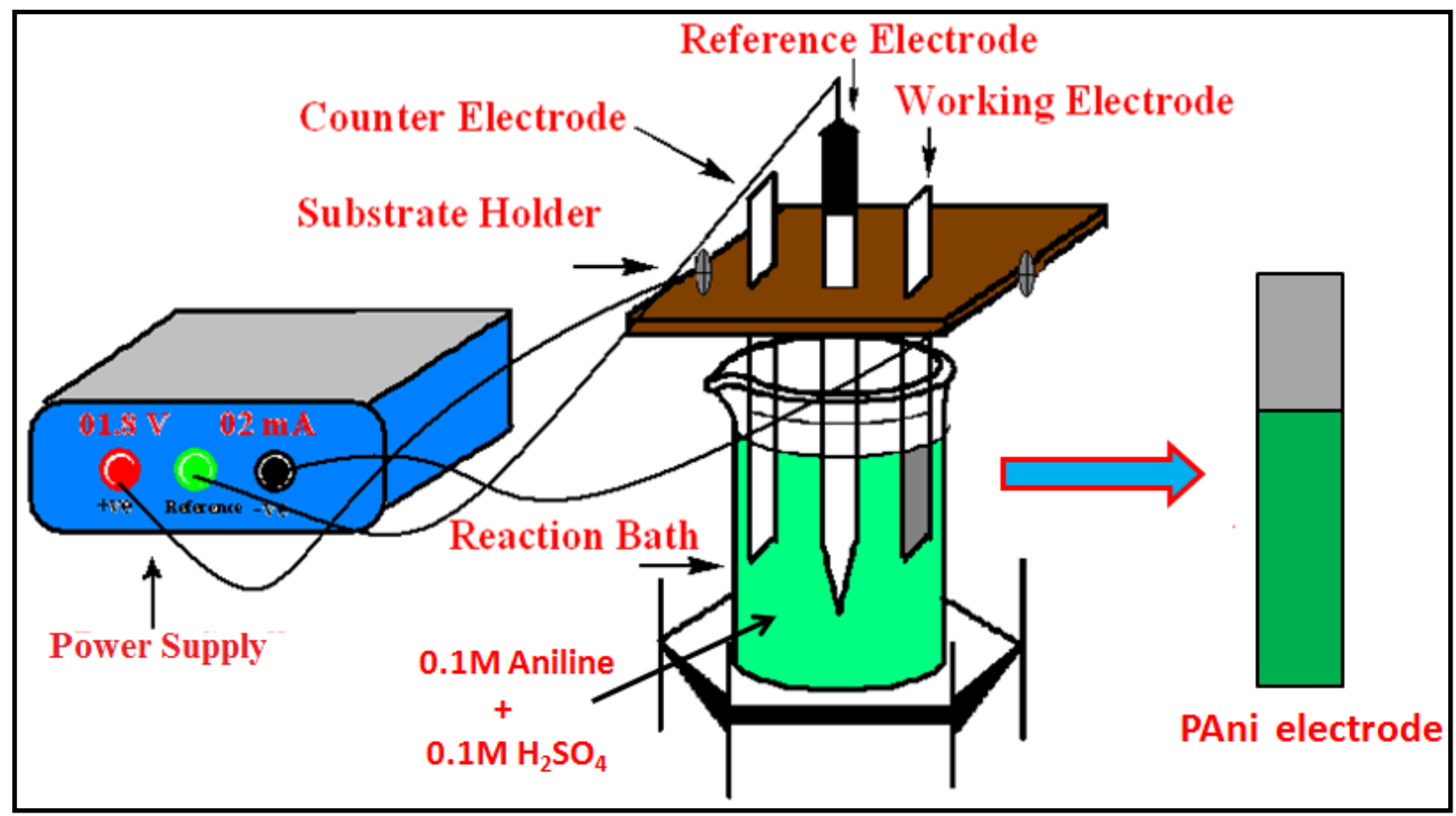

Fig.1. Schematic view of synthesis of PAni electrode. 

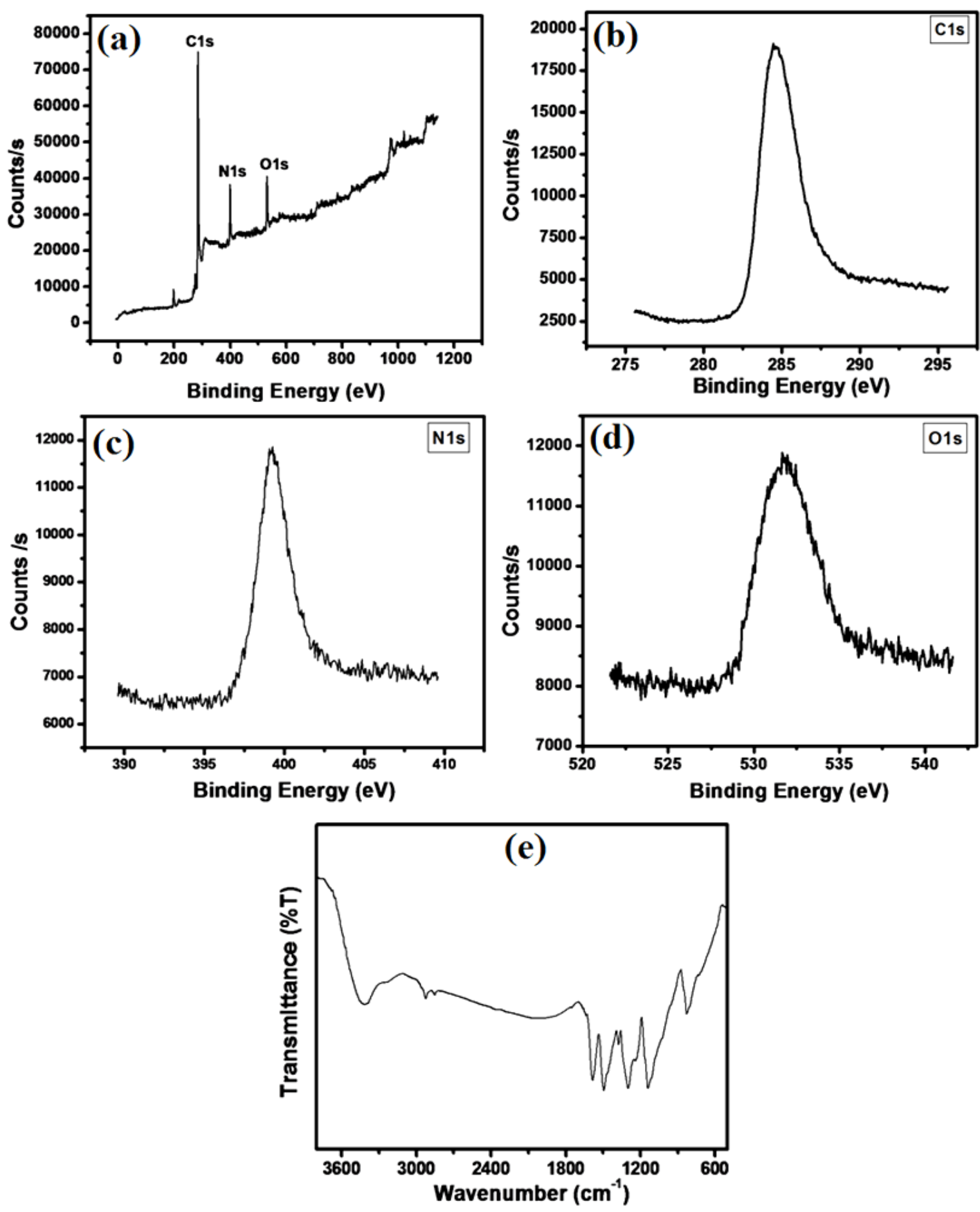

Fig. 2. XPS of PANi film with; (a) wide range scan, (c) C1s (c) N1s (d) O1s core level spectrums, and (e) FTIR spectrum of PAni. 
Fig. 3. (a) FESEM plane-view, (b) AFM, (c) TEM and (d) water contact angle measurement images of PAni electrode. 

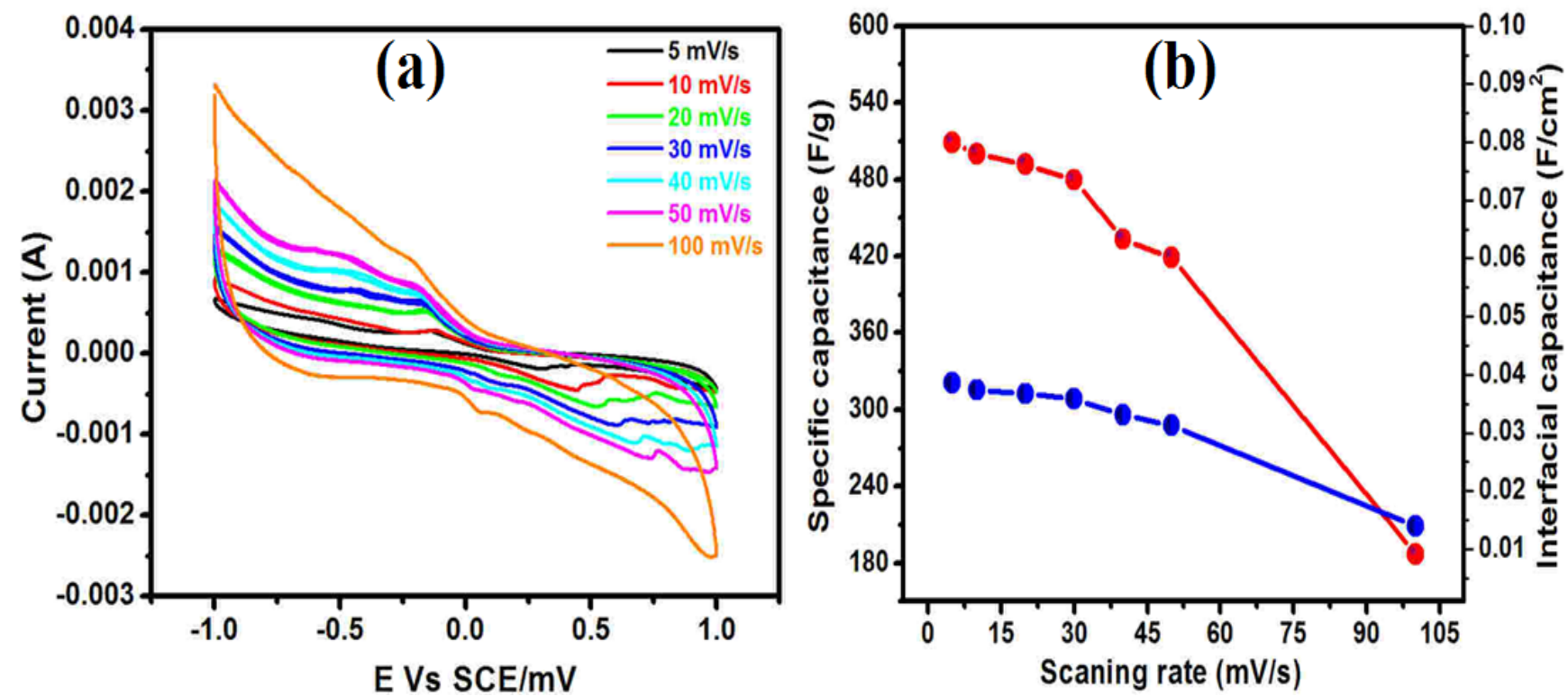

Fig. 4. (a) CV curves and of PAni electrode at different scanning rates and (b) Variation of specific and interfacial capacitances of PAni electrode at different scan rates $\left(5-100 \mathrm{mVs}^{-1}\right)$ in $1 \mathrm{M} \mathrm{H}_{2} \mathrm{SO}_{4}$ electrolyte solution. 

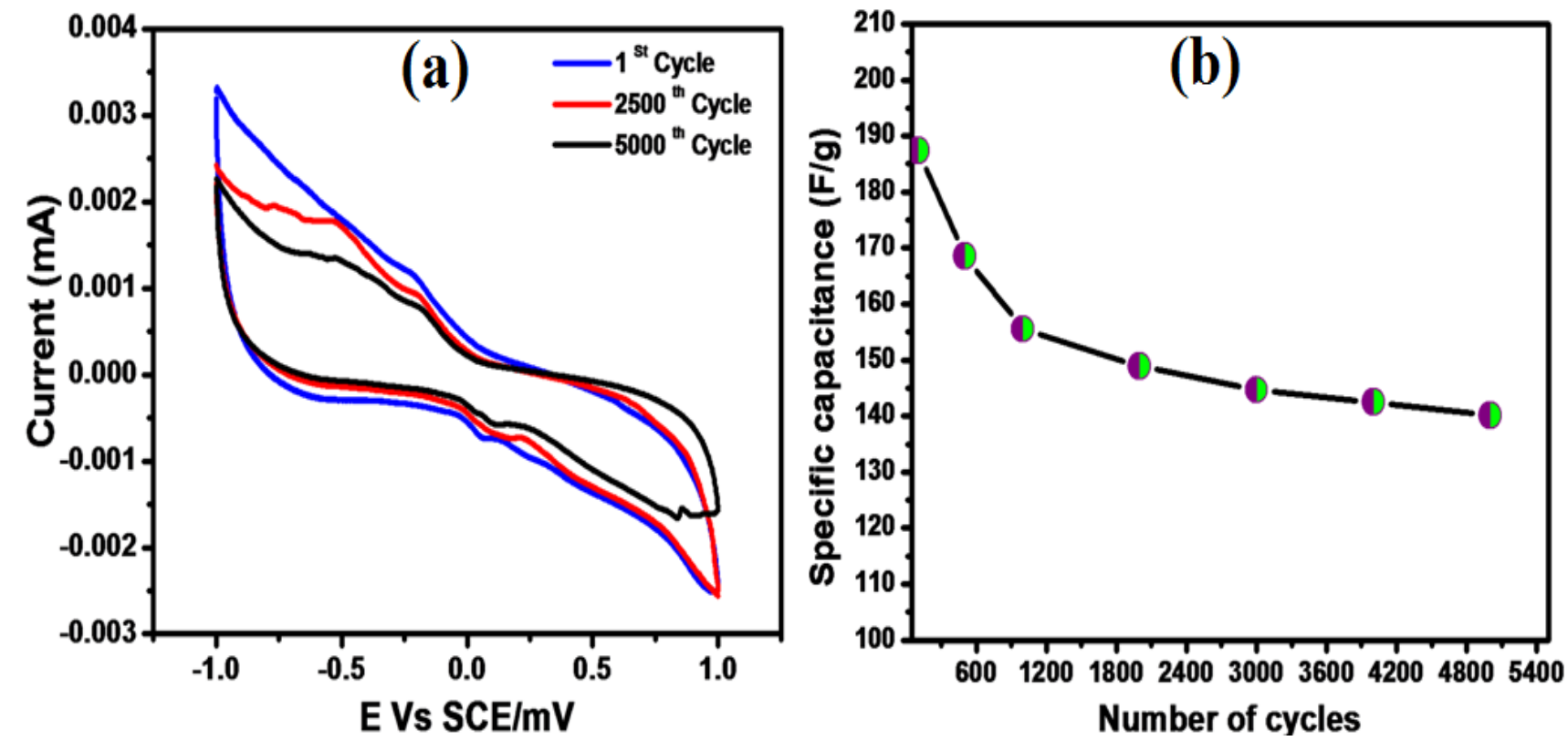

Fig.5. (a) CV scans for 1, 2500 and 5000 cycles and (b) variation of specific capacitance as a function of cycle number of PAni electrode in $1 \mathrm{M} \mathrm{H}_{2} \mathrm{SO}_{4}$ solution at $100 \mathrm{mVs}^{-1}$ scan rate. 

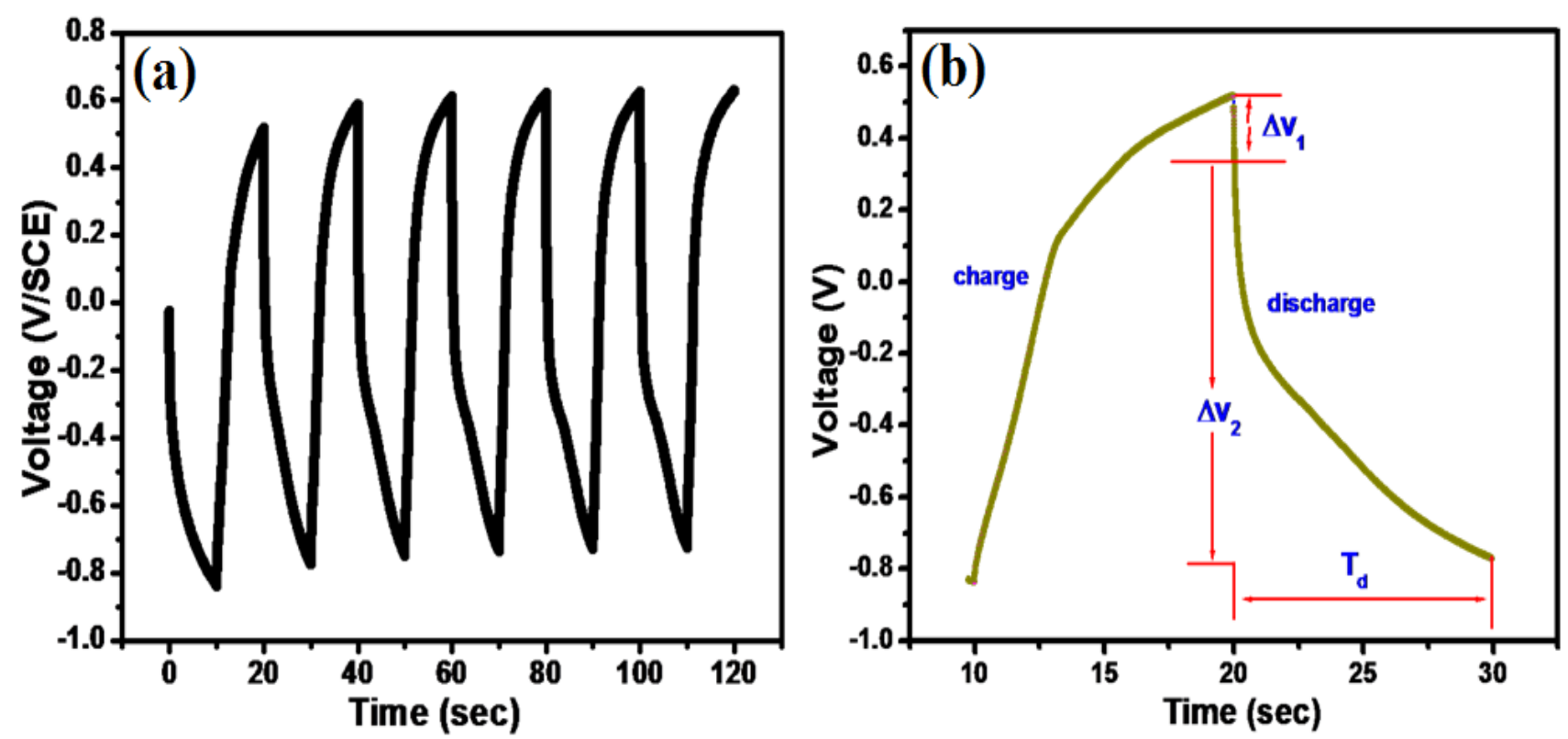

Fig.6. (a) Charge-discharge, and (b) a representative cycle of PAni electrode at $2 \mathrm{~mA} \mathrm{~cm}^{-2}$ in a $1 \mathrm{M} \mathrm{H}_{2} \mathrm{SO}_{4}$ electrolyte solution. 

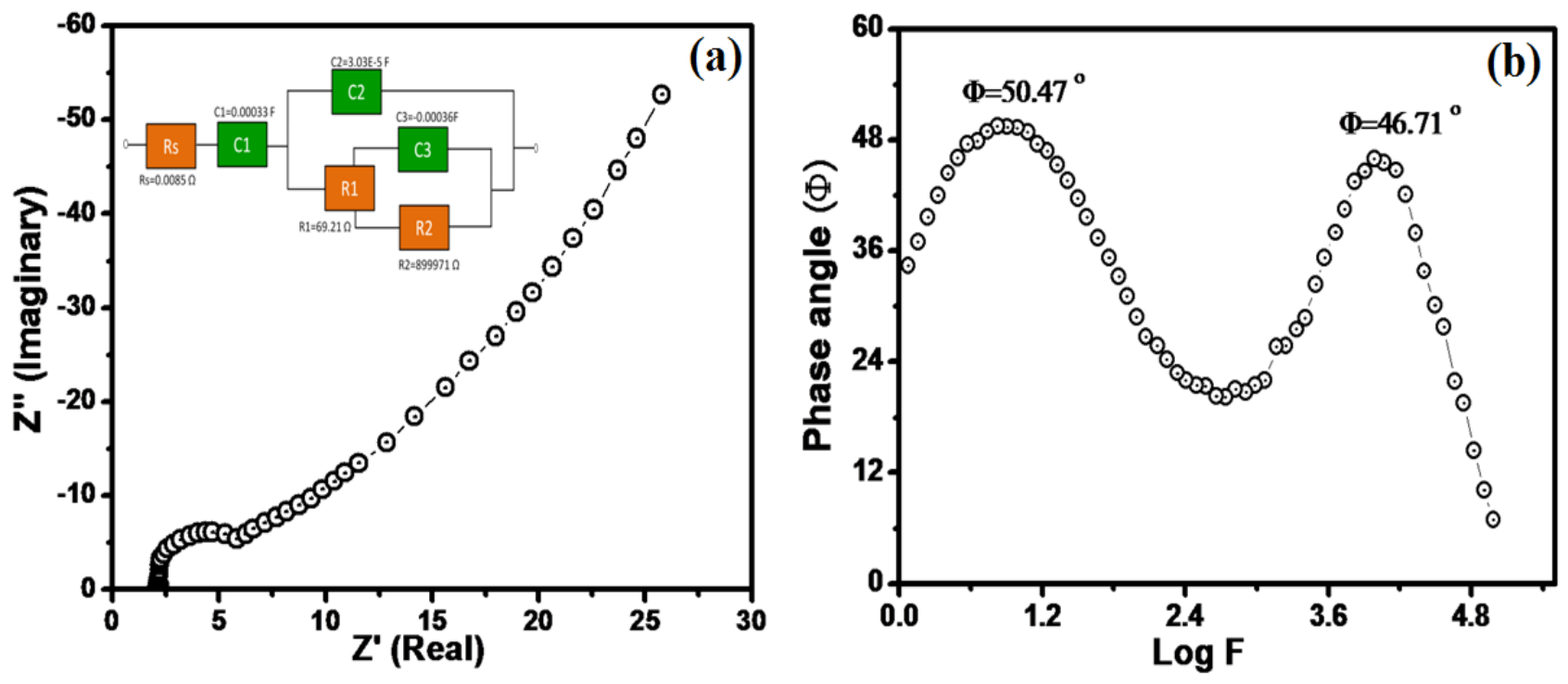

Fig.7. (a) Nyquist plot (inset shows the equivalent circuit) and (b) Bode plot of PAni electrode in $1 \mathrm{M} \mathrm{H}_{2} \mathrm{SO}_{4}$ electrolyte. 


\section{Graphical abstract}

Electrochemical synthesis and potential electrochemical energy storage performance of nodule-type polyaniline

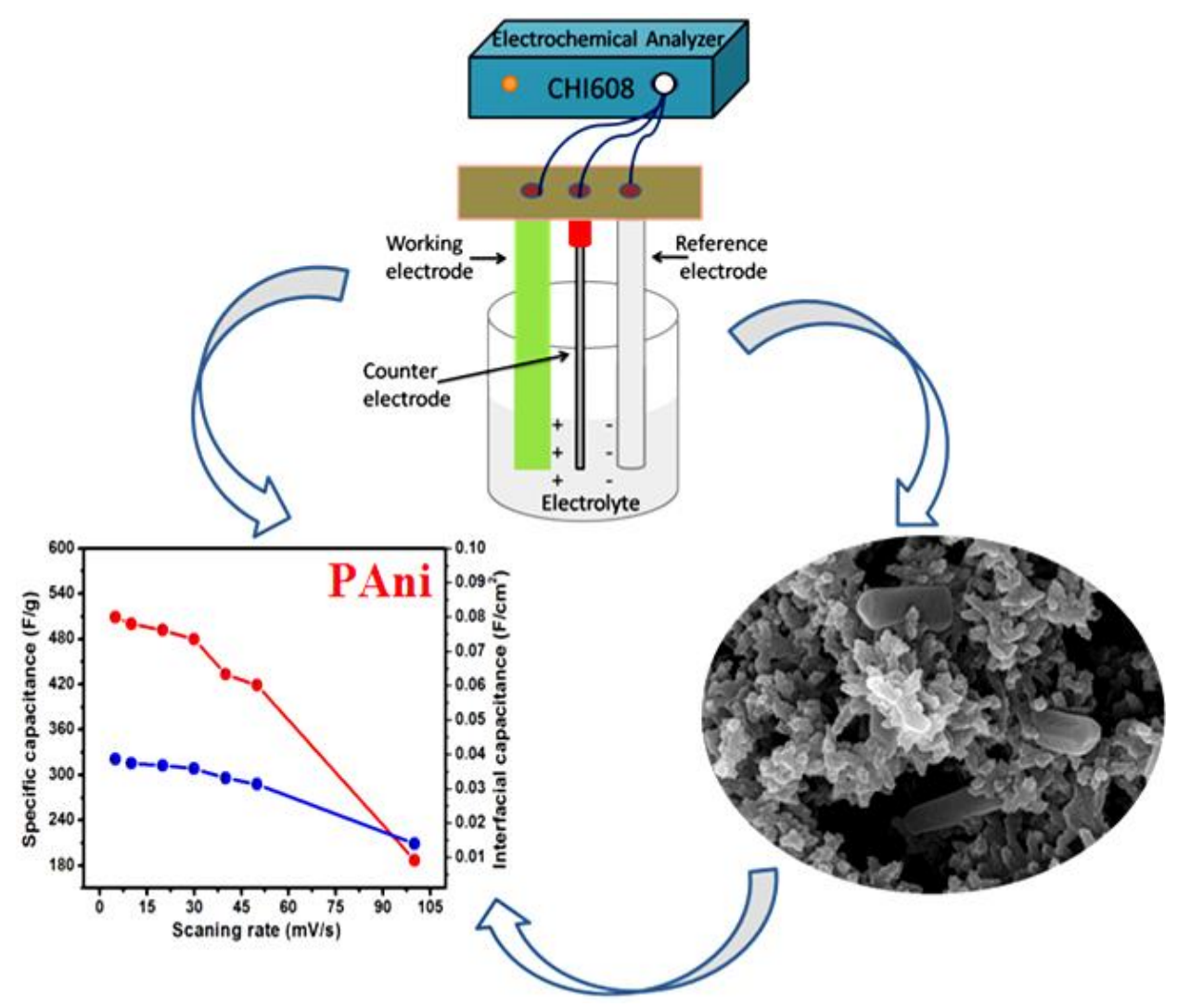

